\title{
Esthetic Rehabilitation of Primary Anterior Teeth using Double Omega Loop Post: A Report of Two Cases
}

\author{
Syed Mujtaba Ali, M. Kiranmayi, S. Srikanth Raju \\ Department of Pedodontics and Preventive Dentistry, Kamineni Institute of Dental Sciences, Nalgonda, Telangana, India
}

Email for correspondence: pedodontist4u2@gmail.com

\begin{abstract}
The most common chronic disease that affects children is dental caries. In particular, maxillary anterior teeth are grossly destructed in early childhood caries. This leads to difficulty in speech, decreased masticator efficiency, development of abnormal tongue habits, and potentially subsequent malocclusion and psychological problems if esthetics are compromised. Restoration of severely decayed primary incisors is often a challenging procedure to pediatric dentists. The present case series documents the esthetic rehabilitation of primary anterior teeth using double omega loop post.
\end{abstract}

Key words: Double omega loop post, early childhood caries, esthetic rehabilitation, strip crowns

\section{INTRODUCTION}

Early childhood caries (ECC) is one of the most common chronic diseases of the childhood. ${ }^{[1]}$ According to the American Academy of Pediatric Dentistry (2003), ECC may be defined "as the presence of one or more decayed, missing (due to caries), or filled tooth surfaces in any primary tooth in a child 71 months of age or younger. ${ }^{[2] "}$ The prevalence is $1-12 \%$ in developed countries, while in India; a prevalence of $44 \%$ has been reported for caries in 8-48-month-old children. ${ }^{[3]}$

The early loss of primary anterior teeth may result in reduced loss of vertical dimension, reduced masticatory efficiency, development of parafunctional habits (tongue thrusting and speech problems), and esthetic functional problems such as malocclusion, psychological problems that can interfere in the personality and behavioral development of the child. ${ }^{[4,5]}$

\begin{tabular}{|l|l|}
\hline Quick Response Code & Article Info: \\
\hline doi: 10.5866/2017.9.10231 & $\begin{array}{l}\text { Received: } 08-11-2017 \\
\text { Revised: } 22-12-2017 \\
\text { Accepted: } 29-12-2017 \\
\text { Available Online: } 12-02-2018,2018 \text { (www. } \\
\text { nacd.in)@ NAD, 2018 - All rights reserved }\end{array}$ \\
\hline
\end{tabular}

In cases of gross destruction of teeth due to caries, endodontic treatment associated with the use of intracanal posts becomes necessary before restoration of the crowns. In primary teeth, intracanal retention can be achieved using several techniques: Directly building up a resin composite post, preparing an "inverted mushroom-shaped" undercut in the root canal before resin composite short-post placement; and using alpha- or omega-shaped orthodontic wire, stainless steel prefabricated posts, nickel-chromium cast posts with macroretentive elements ${ }^{12}$, natural teeth from a tooth bank, or reinforcement fiber. ${ }^{[6-14]}$

This case report describes the challenging task of treating a 2-year-old and a 4-year-old child with severely decayed maxillary anterior teeth that were restored using modified omega loop post followed by strip crown.

\section{CASE REPORT}

\section{Case 1}

A 2-year-old child reported to the Department of Pedodontics and Preventive Dentistry, Kamineni Institute of Dental Sciences, with a chief complaint of blackish discoloration of upper front teeth for 3 months and pain in upper right back tooth region for 3 days. Intraoral examination revealed the 
presence of a complete set of deciduous teeth except for maxillary and mandibular second primary molars. Caries was observed in the following teeth $51,52,54,61,62$, and 64 . Coronal portions of 51, 52, 61 , and 62 were severely damaged, and most of the tooth structure was lost with pulpal involvement [Figure 1]. The caries observed was severe ECC Stage IV. Investigations like intraoral periapical (IOPA) radiographs were taken in respect to 51 , $52,54,61,62$, and 64 [Figure 2a] which revealed the presence of periapical abscess in respect to51, 61 , and 62 and irreversible pulpitis in respect to52, 54, and 64. A treatment plan was formed as follows: Pulpectomy in respect to51, 52, 54, 61, 62, and 64 with semi-permanent esthetic restorations in respect to51, 52, 61, and 62. As the child was very young and due to lack of maturation and cooperative ability the treatment was planned to be performed under general anesthesia. After obtaining parent's consent, pulpectomy procedure was performed under general anesthesia i.r.t. 51, 52, 54, 61, 62, and 64 using metapex [Figure 2b], followed by custom-made double omega-shaped post in respect to51 and 61 [Figure 3]

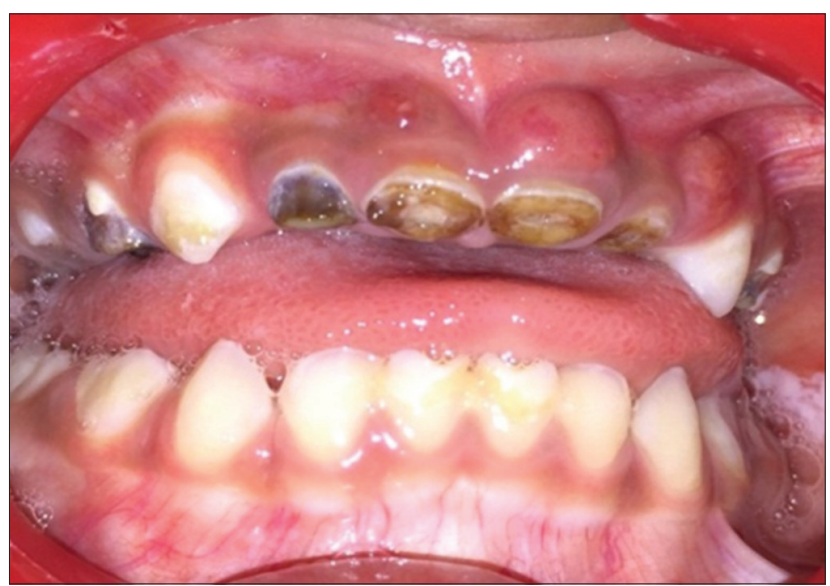

Figure 1: Pre-operative frontal view showing severely decayed $51,52,61$, and 62

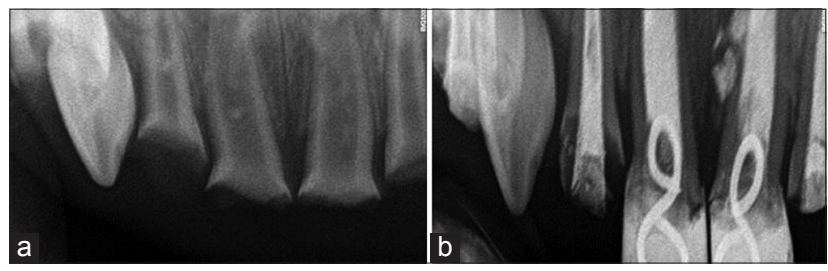

Figure 2: (a) Pre-operative intraoral periapical (IOPA) radiograph showing pulpal involvement of 51,52, 61, and 62 (b) post-operative IOPA radiograph showing obturation with metapex followed by insertion of double omega post in respect to51 and 61 which was constructed with $0.9 \mathrm{~mm}$ stainless steel orthodontic wire using no.130 orthodontic plier to make omega loop, and double omega loop was done to increase the stability of the esthetic restoration and the mechanical retention of the core. About $4 \mathrm{~mm}$ of the metapex was removed from the coronal end of the root canal. The root canal was etched with $35 \%$ phosphoric acid for $20 \mathrm{~s}$, followed by bonding agent application and curing for $20 \mathrm{~s}$. The flowable composite was injected into the root canal along with the loop. The incisal end of the wire projected 3-4 mm above the remaining root structure. The composite was light cured for $40 \mathrm{~s}$. Crown was reconstructed using strip crown [Figure 4]. Finishing and polishing were performed after checking the occlusion.

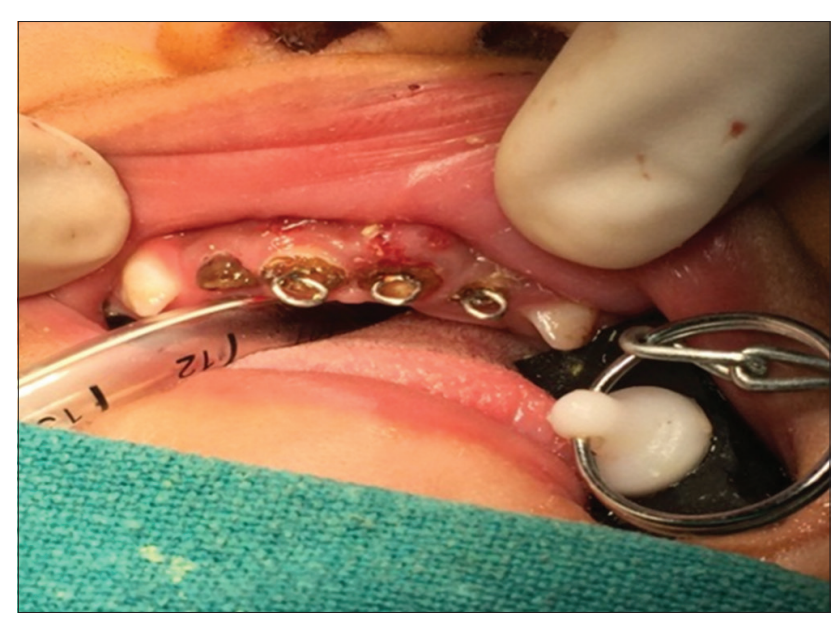

Figure 3: Intraoral frontal view showing placement of double omega posts in respect to51 and 61

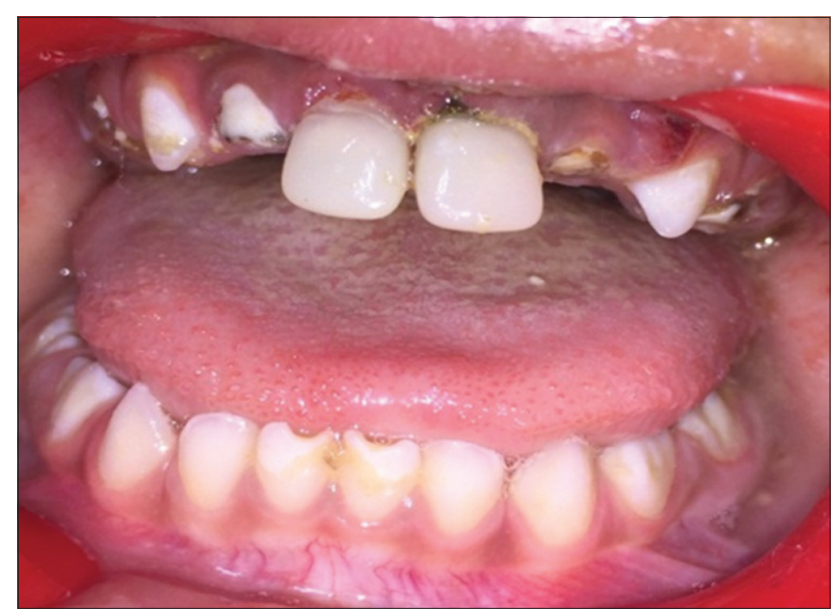

Figure 4: Intraoral frontal view showing final restoration using strip crowns in respect to51, 61 and GIC restoration in respect to52, 62 


\section{Case 2}

A 4-year-old child reported to the department of pedodontics and preventive dentistry, with a chief complaint of pain in upper left back tooth region for 5 days. Intraoral examination revealed the presence of a complete set of deciduous teeth and caries involving in respect to $51,61,64,65$, 74 , and 84. Coronal portions of 51, 61, and 65 were severely damaged, and most of the tooth structure was lost with pulpal involvement [Figure 5]. The caries observed was severe ECC Stage III. After obtaining parent's consent, pulpectomy procedure was performed i.r.t. 51, 61, and 64 using metapex. Custom-made double omega-shaped post was given in 51 followed by reconstruction using strip crown [Figures 6 and $7 \mathrm{a}$ and $\mathrm{b}$ ].

\section{DISCUSSION}

Treatment of preschool children and restoration of primary anterior teeth with the severe loss of coronal structure is a challenging task for the pediatric dentists. The main aim is to preserve teeth and restore them so that child is able to perform normal functions such as mastication, speech, and esthetics. The failure rate is high in such type of cases due to the absence of tooth structure, poor adhesion of bonding agent of primary teeth, limited availability of material, and technique. ${ }^{[5]}$ After the successful endodontic treatment and placement of intracanal retainers, the remaining coronal structure can be restored with indirect or direct technique or single tooth prostheses such as strip crown, stainless steel crown, metal plastic crown, porcelain veneers, polycarbonate crowns, and acrylic resin crown. ${ }^{[15]}$ Nowadays, esthetic crowns are introduced in pediatric dentistry such as Pedo Jacket crowns, Fuks ${ }^{\circledR}$ crowns, New Millennium ${ }^{\circledR}$ crowns, preveneered crowns, Cheng ${ }^{\circledR}$ crowns, Dura ${ }^{\circledR}$ crowns, Pedo Pearl ${ }^{\circledR}$ crowns, and Kinder $^{\circledR}$ crowns to overcome the disadvantages of strip crown like low retention and poor adhesive of bonding agent. These crowns are more durable and less technique sensitive.

Many studies advocate the use of non-metallic posts such as ceramic post, polyethylene glass fibers, and carbon fibers, but in such kind of cases, it has some disadvantages such as technique sensitive, time-consuming, multiple steps, and expensive. ${ }^{[13,16]}$

Rifkin described restoring primary anterior teeth with post and crown. ${ }^{[10]}$ However, it was not widely accepted because of potential for interference with physiological root resorption if the wire extends

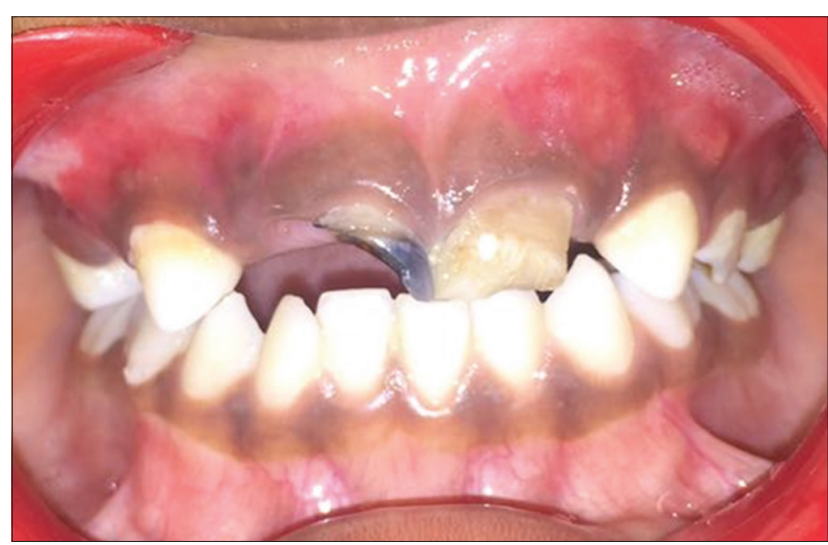

Figure 5: Pre-operative frontal view showing grossly decayed 51

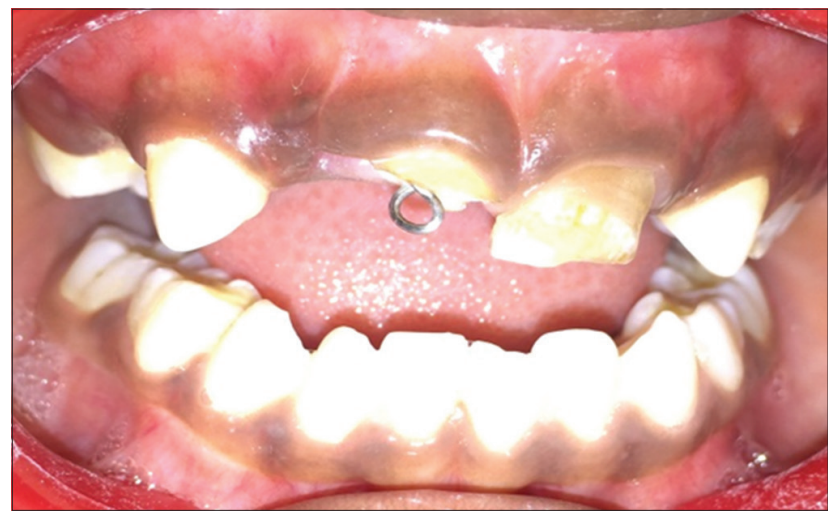

Figure 6: Intraoperative frontal view showing double omega post insertion in respect to51

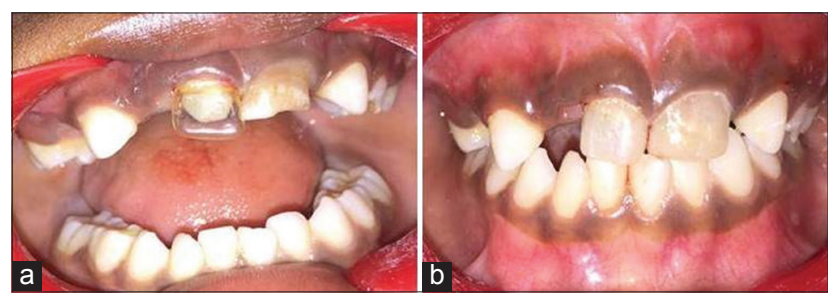

Figure 7: (a) Intraoperative frontal view showing placement of strip crown in respect to51; (b) intraoperative frontal view showing final restoration in respect to51

along way into the root. In addition, it can increase internal stresses within the root leading to fracture if the post is forcibly fitted into a narrow canal.

A simpler and effective method is to use an omega loop that was introduced by Mortada and King. In this technique, omega loops wire extensions are placed at the depth of around 3-4 $\mathrm{mm}$ inside pulp chamber and the projected portion of the loop is used for the retention of the coronal restoration. 


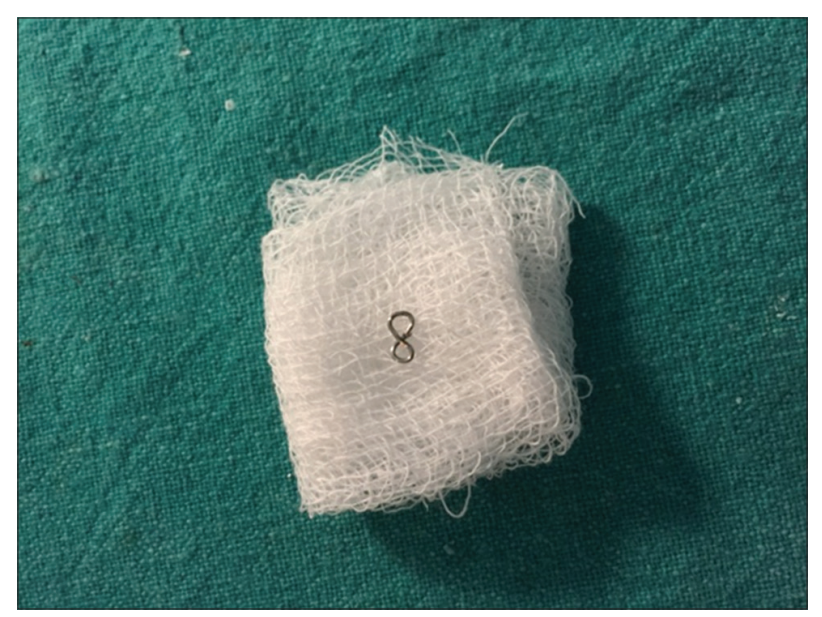

Figure 8: Double omega post

The biggest advantage is that the wire does not cause any internal stresses in the root canal as it is incorporated in the restorative material mainly, and it can be done with minimal chairside time. ${ }^{[15]}$

In the present two case reports, a simple and effective method which was a slight modification of the technique by Mortada and King was used for reconstruction of severely destroyed primary anterior teeth [Figure 8]. ${ }^{[15]}$ The modification to the conventional method was, instead of a single omega loop and wire, a double omega loop was used. This technique can be done directly in the oral cavity without involving any laboratory procedures. The complete procedure can be completed in one appointment, easy for the pediatric patient, and less cooperation required from the child. As the core length of the omega loop, which is placed intracanal, is around $3 \mathrm{~mm}$, thus occupies only the cervical one-third of the canal and does not interfere with deciduous tooth root resorption and permanent tooth eruption. Omega loop technique can be an easier, simpler, and inexpensive treatment of choice for severely damaged primary anterior teeth. ${ }^{[17]}$

\section{CONCLUSION}

The modified double omega loop used in this case report demonstrated good retention, good esthetics, and masticatory function to the child. However, its longtime success and its durability in children having parafunctional habits such as bruxism and deep bite is a matter of further research.

\section{REFERENCES}

1. Mouradian WE. The face of a child: Children's oral health and dental education. J Dent Educ 2001;65:821-31.

2. Verma L, Passi S. Glass fi bre-reinforced composite post and core used in decayed primary anterior teeth: A case report. Case Rep Dent 2011;2011:864254.

3. Jose B, King NM. Early childhood caries lesions in preschool children in Kerala, India. Pediatr Dent 2003;25:594-600.

4. Ngan P, Fields H. Orthodontic diagnosis and treatment planning in the primary dentition. ASDC J Dent Child 1995;62:25-33.

5. Usha M, Deepak V, Venkat S, Gargi M. Treatment of severely mutilated incisors: A challenge to the pedodontist. J Indian Soc Pedod Prev Dent 2007;25:34-6.

6. Grosso FC. Primary anterior strip crowns: A new technique for severely decayed anterior primary teeth. J Pedod 1987;11:375-84.

7. Judd PL, Kenny DJ, Johnston DH, Yacohi R. Composite resin short-post technique for primary anterior teeth. J Am Dent Assoc 1990;14:553-5.

8. Mathias RS, ICramer PF, Imparato JC, Guedes-Pinto AC. Operative and restorative dentistry. In: GuedesPinto AC, editor. Pédiatrie Dentistry. Sao Paulo: Santos; 1997. p. 569-607.

9. Issao M, Guedes-Pinto AC. Pédiatrie Dentistry Manual. Sao Paulo: Pancast; 1978. p. 132-4.

10. Rifkin AJ. Composite post-crowns in anterior primary teeth. J Dent Assoc S Afr 1983;38:225-7.

11. Citron CI. Esthetics in pédiatrie dentistry. NY State Dent J 1995;61:30-3.

12. Wanderley MT, Ferreira SL, Rodrigues CR, Filho LE. Primary anterior tooth restoration using posts with macroretentive elements. Quintessence Int 1999;30:432-6.

13. Vieira CL, Riheiro CC. Polyethylene fiber tape used as a post and core in decayed primary anterior teeth: A treatment option. J Clin Pediatr Dent 2001;26:1-4.

14. Ramires-Romito AC, Wanderley MT, Oliveira MD, Imparato JC, Correa MS. Biologic restoration of primary anterior teeth. Quintessence Int 2000;31:405-11.

15. Mortada A, King NM. A simplifi ed technique for the restoration of severely mutilated primary anterior teeth. J Clin Pediatr Dent 2004;28:187-92.

16. Sharaf AA. The application of fi ber core posts in restoring badly destroyed primary incisors. J Clin Pediatr Dent 2002;26:217-24.

17. Gupta P, Bhatnagar P, Bais PS, Bhatnagar A. Management of mutilated primary anteriors: A challenge to pediatric dentist. Int J Oral Health Med Res 2017;4:45-7. 